\title{
Men, Women, and Economic Changes: Social Representations of the Economic Crisis
}

\author{
Hombres, mujeres y cambios económicos: representaciones sociales \\ de la crisis económica
}

\author{
Ida Galli ${ }^{1}$, Anna Liguori ${ }^{2}$, Fabio Lorenzi-Cioldi ${ }^{3}$ and Roberto Fasanelli ${ }^{4}$
}

${ }^{1}$ Associate Professor at Department of Social Sciences, University of Naples "Federico II", Naples, Italy. E-mail: idagalli@unina.it.

${ }^{2}$ Post Doc at School of Psychology, University of Geneva, Switzerland.

E-mail: anna.liguori83@gmail.com

${ }^{3}$ Full Professor at School of Psychology, University of Geneva, Switzerland.

E-mail: Fabio.Lorenzi-Cioldi@unige.ch.

${ }^{4}$ Assistant Professor at Department of Social Sciences, University of Naples "Federico II", Naples, Italy. E-mail: fasanell@unina.it.

The authors thank Willem Doise, Professor Emeritus at University of Geneva, for his helpful comments on a first draft of this manuscript.

This study was carried out in strict accordance with the recommendations of the Ethic Commission of the Italian Psychological Association and all procedures complied with the guidelines approved by the Members of the National Assembly the $27^{\text {th }}$ of March 2015

\section{Resumen}

La crisis económica actual ha sido un fenómeno nuevo e inesperado; es parte del sistema capitalista, bancario y económico que ha sido conocido hasta el año 2008. La crisis ha llevado a los bancos, los Estados, las instituciones internacionales, así como a las personas del común, a ver profundos cambios en sus representaciones sobre la economía. En este escenario, se plantea la pregunta: ¿cómo los hombres y las mujeres de estratos sociales diferentes afrontan el fenómeno complejo y desconocido de la crisis económica?
¿El género y el estatus social justifican diferentes significados atribuidos a la crisis, sus causas y consecuencias? En el presente artículo se elige la teoría de las representaciones sociales para estudiar el papel del género y el nivel educativo en la producción de las representaciones de la crisis. Se presentan resultados de encuestas realizadas en el sur de Italia $(\mathrm{N}=120)$, los cuales revelan que tanto el género como el nivel educativo de las personas marcan diferencias en la forma de definir y afrontar la crisis. Por un lado, los participantes de alto nivel definen la crisis en términos más abstractos que los participantes 
de bajo nivel. Por otra parte, los hombres de alto nivel mantienen un estado de coping más proactivo con la crisis que los otros participantes, especialmente mujeres. La discusión se enfoca en el papel de la teoría de la representación social entendiendo la relación entre género, estatus y comportamiento económico, aportando ideas sobre cómo la igualdad de género puede ser mejorada.

Palabras clave: Crisis económica; Representaciones sociales; Teoría del Rol Social; Ética del cuidado; Estatus social.

\section{Abstract}

The current economic crisis has been a new and unexpected phenomenon; it is part of the capitalist banking and economic system that has been known until 2008. The crisis has led to banks, states, international institutions, as well as common people, changing profoundly their representations about the economy. In this scenario, some questions arise: how do men and women of different social status face the complex and unknown phenomenon of the economic crisis? Do gender and social status justify the different meanings attributed to the crisis, to its causes and its consequences? When confronted with an external threat like the economic crisis, people draw on social representations to provide meaning to that unfamiliar situation. Through media and interpersonal communication, social groups produce naive theories that improve familiarity with an unexpected and distressing phenomenon. In order to analyze these lay theories elaborated though daily economic thinking and acting, this research has been conducted using Social Representation Theory and its methodological approaches. This theory, in fact, contributes to our understanding of the societal process of sense making when an unexperienced external shock affects society. It offers a way to understand economic phenomena's impact on social groups. Social representations (SRs) serve the purpose of making the unfamiliar become familiar, and the unusual become usual, as well as to provide orientation in times of change. In this sense, in this article, social representations theory is used to examine the role of gender and educational status in the production of representations of the crisis.

Presented findings came from a survey carried out in Southern Italy $(\mathrm{N}=120)$ revealing status and gender differences in the ways people define the crisis and cope with it. Participants were asked to order the first most important five statements and the first least important statements, among a list of 15 (according to the rule of a multiple of 3 ) to code every item with a score of 1 (less characteristic), 3 (more characteristic), or 2 (not chosen). Every Questionnaire of Characterization was created starting from social descriptions and explanations of the crisis, identified in a previous study. They covered every sub-dimension of the content (complementary to the structure) of the social representation of the crisis, such as: cognitive-evaluative aspects about the representation's structure (central and peripheral elements); descriptive-defining aspects of the representation; informative sources and interaction networks; level of involvement/implication with the object; relationship between representation and social practices; perceptions, attributions and categorizations (causes, responsibilities, duration/evolution, solutions, positive implications, the EU's role). In this paper, we will only consider the answers related to the following dimensions: crisis definitions, strategies to tackle the crisis and social practices related to the crisis. The analysis of the data was carried out primarily using Multiple Correspondence Analysis (MCA). In this analysis, in order to uncover the objectification and anchoring processes, we considered the interaction of status and gender as an illustrative variable. These findings were further substantiated with the use of Discriminant analysis. The social anchoring of social representations of the economic crisis is influenced by gender and 
social status. Nevertheless, the difference in status modifies the stereotypical dimensions, also coherently with predictions derived from gender role theory about the reduction of the impact of gender stereotypes when men and women occupy similar social positions. On the one hand, high-status participants defined the crisis in more abstract terms than low-status participants. On the other hand, high-status men hold a more proactive style of coping with the crisis than other participants, especially women. The discussion focuses on the role of social representations theory in understanding the relationships between gender, status and economic behavior, providing insights into how gender equality might be improved.

Keywords: Economic crisis; Social representations; Social Role Theory; Ethic of care.

\section{Introduction}

"Crisis is not the same for everyone" claims the title of a book by the Italian economist Tito Boeri (2009) to stress how differently members of various social groups have experienced the impact of the financial and economic crisis. The financial crisis began in 2007 with a "credit crunch", and evolved in 2012 as a sovereign debt crisis. It first hit the US, and then Europe and its monetary union architecture, and called into question not only the capitalistic and banking systems, but also the traditional ways in which financial crises are "gendered". The economic crisis, in fact, increased social inequality, especially in job access and welfare (European Commission Report, 2013). Compared to men, women's already lower tendency to be employed and their ensuing lower "covering" by social insurance systems has made them even more vulnerable to cuts and savings of welfare spending. Thus, social welfare coming from employment accentuated the gap between better-and worse - protected groups (Macleavy, 2011). Without an adequate public expenditure to cover increased child-care costs or maternity pay, formerly rather efficient welfare systems (such as in the UK and Ireland) began encouraging "male breadwinning and female caring" roles (Koole \& Vis, 2012, as quoted by the European Commission Report, 2013).

In this complex scenario, men lose their jobs more often than women do, experiencing frustration for not being able to assume the typically masculine role of the breadwinner anymore. As for women, they engage in new roles, in some cases even that of breadwinners, without being able to reconcile efficiently work and traditional female roles (European Commission Report, 2013).

Also in Italy, where the effects are more limited than in other European countries (European Commission Report, 2009, 2010; OECD, 2009, 2010), the crisis affected men even if they were better protected by social safety nets (Altieri, 2010). However, it seems to have worsened the structural problems of female employment (segregation, flexibility, conciliation) (Istat, 2011). These dynamics occurred in a labor market profoundly changed when compared to the crises of the previous years. In particular, matched to the early ' 90 s, labor market today registers certainly a greater female presence and a considerable weight of the unstable work. In the new, more flexible, market, the spaces for women have expanded. This rise has been driven by the spread of higher education and the gradual dematerialization of the economy, but also from the flexibilization of the market. That process has certainly made it more a dynamic confrontation between supply and demand, but it has generated high levels of job instability, which is thickened female employment. In the middle of the crisis, women accounted for over $53 \%$ of unstable employment, although they constituted just over 39 $\%$ of total employment (Altieri, 2009). In the South of Italy this phenomenon is relatively wide and persistent, and especially interesting in the adult age group (35-54 years), where almost 1/4 woman are occupied. Therefore, 
the effects produced by the process of flexibility show a very contradictory reality, made of the development of opportunities, the lack of stability and remuneration. The growth of female employment has been very significant and represents much of the increase in employment recorded in the last two decades. Anyway, the employment rate-in Italy $12 \%$ lower than EU-have negatively influenced the differences between the Centre-North and the South of the Country. The increasing non-participation in the work of Southern women contributes to depress the rate of the national average occupancy, making the target agreed at the EU Lisbon Treaty in 2007 (female employment rate to $60 \%$ ) a distant utopia (Altieri, 2010).

This socio-economical background inspired the following research questions: How do these men and women living in a period of crisis conceive of, and cope with, the situation? How do they build their social knowledge about this complex and unfamiliar phenomenon, starting from their gender and social status?

\section{Theoretical framework}

When confronted with an external threat like the economic crisis, people draw on social representations to provide meaning to this unfamiliar situation. Through media and interpersonal communication, social groups produce "naive theories" that improve familiarity with an unexpected and distressing phenomenon. In order to analyze these lay theories elaborated though daily economic thinking and acting, this research has been conducted using Social Representation Theory (Moscovici, 1961) and its methodologies. This theory, in fact, contributes to our understanding of the societal process of sense making when an unexperienced external shock affects society (Puashunder, 2012). It offers a way to understand economic phenomena's impact on social groups. Social representations (SRs) have the function to render familiar the unfamiliar and usual the unusual (Moscovici, 1984b) as well as to provide orientation in times of change (Moscovici, 1984a). Through capturing discourse and knowledge-exchange in the social compound, social representations thereby allow delineating dynamic processes of socio-economic adaptation (Kirchler, 2007; Vergès, 1994). For these reasons, in line with the tradition of economic psychology, the study of social representations of economics is crucial to identify different types of financial behaviours (Roland-Lévy, \& Adair, 1998). The objective of social representations research in the economic area is to understand "how ordinary people perceive economic phenomena" (Vergès \& Bastounis, 2001, p. 25)

Social representations are generated by two main processes, objectification and anchoring. Objectification consists of the transformation of an abstract and unfamiliar object into an image or figurative scheme (Lorenzi-Cioldi, 1997; Moscovici, 1984). As Staerklé, Clémence and Spini (2011, p. 761) emphasize:

"Objectification refers to the transformation of general or scientific ideas into concrete and useful forms of knowledge. This process produces shared figures or symbols which incorporate the meaning of the original ideas, but which can be more easily used in everyday communication. [...] However, this does not mean that all group members would share the same knowledge. The objectified symbols must indeed be incorporated in established and familiar beliefs which in turn depend on the social group individuals belong to."

The anchoring process, for its part, corresponds to the incorporation of new elements of information into a more familiar, existing knowledge (Doise, Clémence, \& Lorenzi-Cioldi, 1993). It allows to transfer something unknown and potentially threatening into an established and working categorical system (Galli, 2006) that depends on the specific positioning of individuals and groups in the social structure. Individuals or groups, in fact, give weight to different dimensions of 
representation because of their anchoring in collective symbolic realities, in shared social psychological experiences, and in their beliefs about social reality (Spini \& Doise, 1998).

Doise (1992; 2010), focuses on the social aspects of this process. He mentions three possible levels of anchoring: the psychological, the psycho-sociological, and the sociological. The latter one refers to the links between representations and individuals' specific belongings into groups and to their shared social relations. It assumes that different social insertions provoke different experiences and exchanges, which influence their social representations.

To explore the correlation between gender differences - related to the positioning of men and women in the social structure-and social representations of the crisis, we also used the perspective of Social Role Theory (Eagly, 1987; 1997). Following Eagly's work, these differences refer to masculine or agentic characteristics (e.g., dominant, assertive and boastful) versus feminine or communal characteristics (affectionate, gentle, and sensitive; see Wood \& Eagly, 2010). The main idea of this theory is that gender differences and similarities in behaviors mirror beliefs about men's and women's roles in the society at large (Eagly \& Wood, 2012). In particular, communal traits assigned to women are considered as low-status traits, whereas the agentic traits assigned to men are high-status traits (Fiske, Cuddy, Glick, \& Xu, 2002; Ridgeway, 2001). Lastly, we interweaved that approach with the "different voice" perspective asserted by Gilligan (1982). Her standpoint distinguishes between gendered ethical ways of being and reasoning. Women would be more oriented towards the care as well as a real and practical view of life, whereas men would be more oriented toward abstract justice and rights views.

In general, Social Role Theory emphasizes social forces such as cultural norms, gender stereotypes and gender role expectations, whereby Social Representations, according to
Doise (1990), are structured around 'organizing principles', understood to be questions or topics leading to specific viewpoints that depend upon the social positions of individuals. Interrelations between these two approaches, in our opinion, are useful to emphasize individual differences, assuming that these are larger than gender differences. In this sense, as underlined by Malach Pines, Lerner and Schwartz (2010), some researches have shown that working women, especially in high positions (Diekman \& Eagly, 2000) are a heterogeneous group, with different backgrounds, aspirations and experiences and their similarities to men are at times larger than the differences.

\section{Aim of the study}

With the aim of investigating the role of shared group memberships and to search for patterns of individual differences-linked with them-we explored how participants' gender and status shape their social representations of the crisis. More specifically, we examine how men and women, of different status positions, anchor the economic crisis. In other words, the fact that females are considered more "communal" and men more "agentic", or that the rationality of women is more "practice-oriented" than men's "abstract" one, turns out to be a socio-cultural construction rather than a dispositional orientation.

In particular, starting from Eagly's theory (1987), we expect that, representing and facing the crisis, men would express more agentic meanings and women would express more communal meanings. Thus, following Gilligan's (1982) perspective, we expect that men should be more oriented toward abstract ways of reasoning, while women should engage in more practical ones.

\section{Method}

The data come from a large international survey (Galli, Geka, Liguori, \& Fasanelli, 2014; 
Galli, Markova, Bouriche, Fasanelli, Geka, Iacob, \& Iacob, 2010; Liguori, Galli, Fasanelli, $\&$ Iacob, 2014) on the social representations of the economic crisis. The survey was carried out in Italy, Greece, Romania and France, in 2009 and in 2012. In this paper, we only refer to the Italian subset of the 2012 study.

\section{Sample}

Four groups of participants $(\mathrm{N}=120$ for each country; $n=30$ for each group; gender balanced, aged 20 to 60 years old) were employed: university students (second/third year; Faculty of economics), mid-level bank clerks, shopkeepers, and laypeople. Strategies adopted to contact interviewees vary in each group: students have been reached at university, between classes; bank clerks were contacted and interviewed by making appointments at their work place and choosing people from agencies in relations of collaboration or geographical proximity; shopkeepers have been interviewed on appointment and at their work place too; laypeople have been contacted in the street, next to/inside shops.

\section{Data collecting strategies}

Studying a social representation, in the Structural approach (Abric, 2003) means, first of all, to find out the constitutional elements of the structure. In this theoretical framework, to reach the "significant elements" of the social representation of an economic crisis, and to reconstruct the organization of these elements, it has chosen to use the Method of Hierarchized Evocation. In the first part of the interview, after an open question about the social definition of the "crisis", the participants were asked to answer to a free associations and consequent hierarchisation task, as Vergès' method provides (Vergès 1994; Vergès \& Bastounis, 2001). Besides, the free association task was completed by open questions about the subjective justification linked to every associated term, with the aim to avoid lexical ambiguity, which is typical of this kind of data (Fasanelli, Tuselli \& Galli, 2016; Galli, Fasanelli \& Schember, 2018; Marzana, Pozzi, Fasanelli, Mercuri \& Fattori, 2016). Vergès (1994) states that with the interview it is possible, on one side, to reach the SR's structure and, on the other, to show how this structure can be translated in argumentation. For that reason, in the second step of the whole research, to access the content of the SRs of the economic crisis, a series of "questionnaires of choice" and "questionnaire of characterization" (Vergés \& Bouriche, 2009, pp. 85-87) were constructed starting from social descriptions and explanations of the crisis, identified in the previous study made up by an intercultural team (Galli, Markova, Bouriche, Fasanelli, Geka, Iacob \& Iacob, 2010).

\section{Data analysis techniques}

The terms evocated by the participants were firstly treated with a lexical and categorical analysis. In the lexical phase, they were aggregated on the basis of the synonymy criterion in order to obtain clusters of terms substantially coincidental with the "manifest meaning" (Bardin, 2003). Therefore, using a semantic criterion, terms have been further aggregated starting from their justifications. Each of the obtained clusters was associated with a new label. Every label was identified using, as a selective criterion, the high semantic proximity and frequency of occurrence inside every aggregation of terms. The obtained data was finally processed by specific software (Evoc2005, IRaMuTeQ). The hierarchized evocation analysis was allowed to reach the elements, which constitutes the central core and the periphery of the social representation of the economic crisis, for each group of participants. Similitude analysis (Flament, 1962; Vergès \& Bouriche, 2009) supported by software like Simi2005 or IRAMuTeQ, has the advantage to better show the organizational structure of the significant elements of every SR. 
Data from questionnaires of choices and characterization were treated by using a Similitude analysis, not only in a traditional way, but furthermore in a multidimensional procedure.

Moreover, a descriptive analysis (SPSS supported) was conducted on all the variables to verify the presence of differences among the samples (Chi-square test).

In the following, the ways Italian participants define the socio-economic climate and the crisis, and the strategies they use to cope with the crisis were addressed. Also responses to some of the "characterization questionnaires" included in the collection data strategies were analyzed. Participants were presented with 15 statements and were asked to choose the five most important and the five least important. The statements were coded 1 (least important), 3 (most important), and 2 (not chosen). They covered every sub-dimension of the "content" (complementary to the structure) of the social representation of the crisis, such as: cognitive-evaluative aspects about the structure of the representation (central and peripheral elements); descriptive-defining aspects of the representation; informative sources and interaction networks; level of involvement/implication with the object; relationship between representation and social practices; perceptions, attributions and categorizations (causes, responsibilities, duration/evolution, solutions, positive implications, the EU's role).

In this paper, were only considered the answers related to the following dimensions: crisis definitions, strategies to tackle the crisis and social practices related to the crisis. Analysis of these data was carried out using multiple correspondence analysis (MCA). In this analysis, we considered the interaction between status and gender as an illustrative variable. Based on previous evidence of a relationship between education and social class (e.g., Braveman et al., 2005; Weiss, \& Fershtman, 1998), we used participant educational level as a proxy for participant social status (see Stephens, Fryberg, Markus, Johnson, \&
Covarrubias, 2012). Participants with a university background were considered of high status (HS), and participants with a primary or secondary school diploma were considered of low status (LS). The sample $(\mathrm{N}=120)$ was thus split into four groups (28 LS men, $28 \mathrm{LS}$ women, $32 \mathrm{HS}$ men, and $32 \mathrm{HS}$ women). MCA is a suitable statistical approach to uncover the objectification and anchoring processes (see Doise, Clémence, \& Lorenzi-Cioldi, 1993). It is particularly useful when the complexity of relations between responses makes the overall structure difficult to appreciate. The technique not only detects links between components of the social representation, but also sheds light on the relationships between these components and the respondents' group memberships, in the present case on the basis of gender and social status. Indeed, illustrative variables (social positions) are placed by MCA at the center of the subset of the social representation's components to which they are closest. In this way, the membership groups of the respondents are projected into the space of responses and thus, in a way, of the representation. In sum, this procedure is similar to a two-steps method that consists of factor analyzing the data, then computing individual positions on factors (factor scores), and performing analysis of variance of these positions according to variables external to the analysis. But MCA offers the advantage of providing a simultaneous depiction of responses and respondents' characteristics.

\section{Results}

We used Eagly's (1987) and Gilligan's (1982) theoretical frameworks to interpret the MCA dimensions. Both approaches distinguish between men's agency (autonomy and separateness) and women's communion (connection to others and relatedness). But whereas for Gilligan men and women evolve in rather different spheres, for Eagly's social role theory the status dimension is essential in building gender representations. Indeed, 
the agentic and communal qualities typically attributed to men and women are rooted in the gender division of labor. Sex differences and similarities in behavior reflect people's observation that most men fulfil professional roles that require agentic qualities (e.g., managers, engineers, etc.) and that most women fulfil professional roles that require communal qualities (e.g., caregivers, elementary school teachers, etc.). In this process, people construct gender roles that appear to be stable, inherent properties of men and women.

The MCA findings are shown in Figure 1 (39 active variables, and one illustrative variable consisting of the interaction between gender and status). The two dimensions show eigenvalues of 3.98 and 2.88 and explain 10.21 $\%$ and $7.38 \%$, of the total inertia respectively. To interpret the dimensions, we considered the most important variables, that is those reaching at least .026 (that is, 1/39) of contribution to the inertia of the dimension. The first dimension (horizontal) opposes an abstract to a practical pole, that is a "macroeconomic" to a "microeconomic" image of the crisis. Toward the abstract-macroeconomic pole there are various technical and macroeconomic definitions of the crisis (phase of economic cycle; offer excess/supply reduction; unemployment increase; saving and investments reduction; banks and finance dysfunction; conspiracy), and the most ideal strategies to face it (I participate more in the political life; I help the weakest materially and morally; I get more informed on politics, economics and finance; I wait for market equilibrium coming back; I save more; I share what I have with others;
I privilege public transports). On the practical-microeconomic pole appear definitions oriented towards individual-level behaviors (Reduction of consumption and sales, Stress and frustration, General distrust, Uncertainty of future, Prices increase, Slump of purchasing power, Salaries reduction), and a cluster of strategies related to daily ways to react to the economic crisis (I keep more engaged in my work, I bet, I do more than one job, I stay more often at my place watching TV, I buy just low quality brand products, I find alternative ways to have fun).

On the second dimension, a proactive and coping oriented image of the crisis opposes a resigned and negatively defining image. On the coping pole there is a prevalence of strategies to cope with the crisis, while on the defining pole negative descriptions of the crisis prevail.

The location of the gender $\times$ status modalities of the supplementary variable shows a status effect along the abstract (HS men and women) versus practical (LS men and women) dimension. The gender effect, instead, shows up only on the residual second dimension, going from the coping and strategic (men) pole to the resigned and negatively defining (women) pole. Consequently, the abstract versus practical continuum can be considered as a status dimension, while the coping versus defining continuum can be considered as a gender membership dimension. Besides, we can advance that men (vs. women) are more often proactive (vs. resigned), and that HS participants (vs. the low status) are more often idealistic and macroeconomic oriented (vs. practical and micro oriented). 


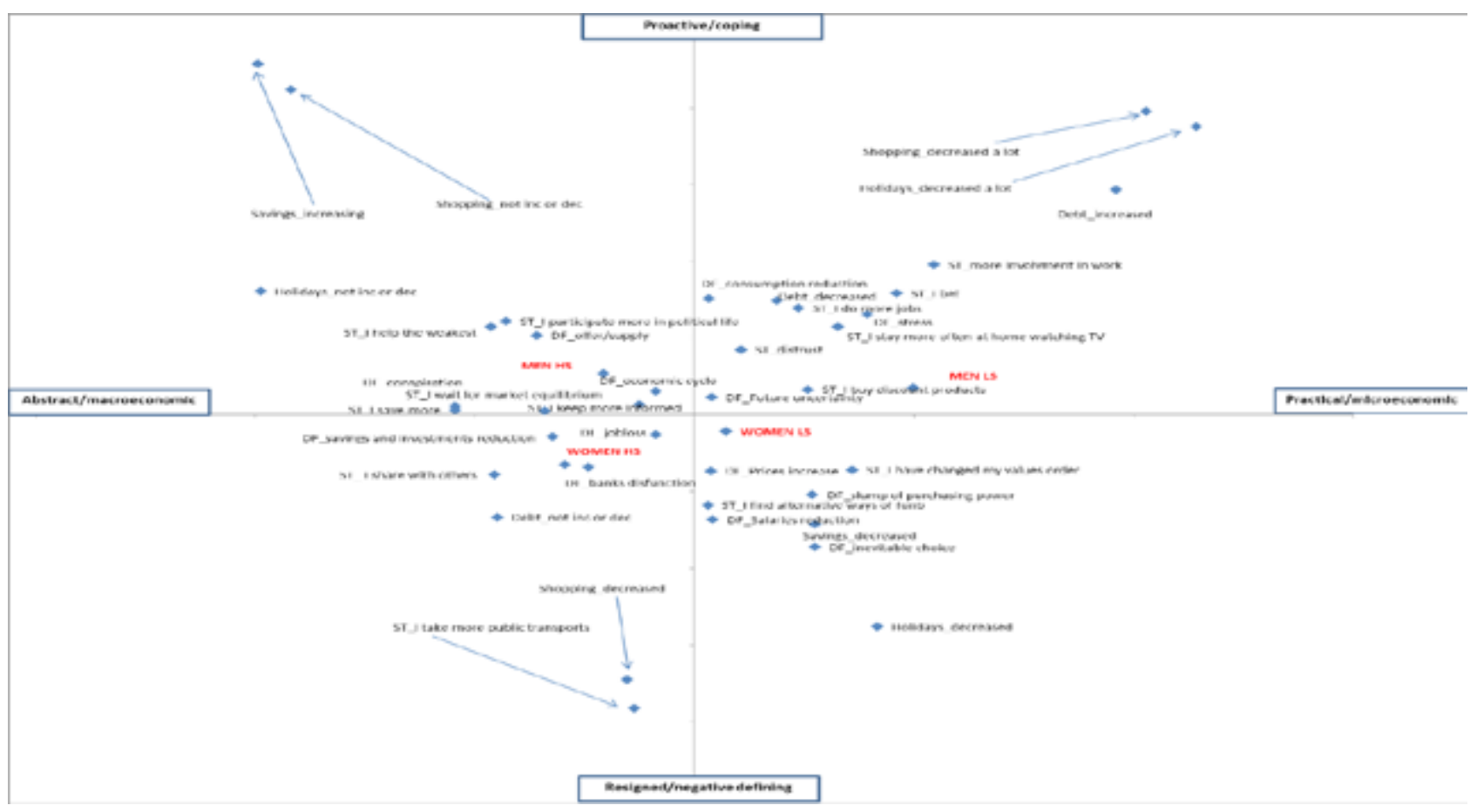

Figure 1. Multiple correspondence analysis. Definitions (DF), Strategies (ST), Behaviors (Shopping; Debt; Savings; Holidays) of high and low status men and women on two dimensions.

Testifying to this stronger effect of status and complex interaction between status and gender, a further Discriminant analysis on the same variables, with the status $\times$ gender interaction as a discriminating criterion, produced a single significant discriminant function (Wilk's Lambda $=.22, \mathrm{p}<.02$ ). This function opposed LS men (centroid $=-1.36$ ) to HS men (1.47), with women laying less markedly on the corresponding poles (LS $=-.60$ and $\mathrm{HS}=$ .24). A Discriminant analysis using only participant gender as a discriminating criterion did not produce a significant discriminant function, whereas the one using participant status did (Wilks's Lambda $=.53, \mathrm{p}=.005$ ).

In sum, by considering the positioning of the participants on the two MCA dimensions we can delineate four distinct social representations of the economic crisis. The abstract, coping oriented representation consists of HS men who define the crisis as a phase of the economic cycle, and in terms of excess offer and supply reduction. They emphasize an increase of savings, but no modifications of other practices like holidays and shopping. In concert, they claim they would wait for better times (the market equilibrium). These participants also endeavor to keep informed, to save more money, to increase participation in politics, and to help the feeble.

HS women hold a more abstract but negatively defining representation. They envision the crisis in terms of unemployment, savings and investment reduction, and malfunctioning or banks conspiracy. They further claim a decrease in shopping and react to the situation by privileging public transportation and sharing more with others.

In opposition to HS men, there is a coping oriented but practical representation among LS men, who define the crisis as stress and frustration, consumption and sales reduction, general distrust, and uncertainty of future. These participants claim a huge decrease of shopping and holidays, and react with more work and more jobs, buying discount products and proactive betting.

Instead, a practical and resigned representation of LS women defines the crisis as prices and salaries reduction, and slump of 
purchasing power. In their opinion, crisis is something inevitable. It hampers holidays and savings and brings them to react finding alternative ways of fun and changing their value systems.

\section{Discussion}

The representational field of the economic crisis is organized along two main dimensions: the abstract/practical dimension, and the coping/defining dimension. It appears that the objectification of the crisis fits quite well with Gilligan's and Eagly's models, but with some differences according to the model. While Gilligan's opposition between abstract and concrete emerges quite clearly as an abstract versus practical dimension, Eagly's construct of the communal and the agentic emerges on a further dimension as a defining (not a communal) versus a coping pole. The two identified dichotomies differently objectify definitions and strategies related to the crisis, creating four different profiles: idealistic and agentic HS men; idealistic and negatively defining HS women; agentic and practical LS men; and practical and negatively defining LS women. Overall, then, the MCA findings complement the Discriminant analysis findings to portray a strong social status opposition, and a gender opposition of lesser magnitude.

The structuring of these dimensions allows us to infer some other important differences between crisis SRs related to Gilligan's and Eagly's frameworks. First, although the first MCA dimension (as does the single significant discriminant function) appears to objectify Gilligan's opposition between abstract and practical. At the same time, it does not generally oppose men to women, as one would expect, but HS participants to LS participants. Because the opposition seems to be stronger when considering the status combined with gender rather than the gender of the status alone, this suggests that social status interacts with gender in the production of the represen- tations of the crisis, coherently with the role of status in the model proposed by Eagly and Wood (2012).

Referring to the proactive versus defining dimension, instead, we observe a gender-membership polarity that is coherent with the general stereotypical idea of men as more agentic than women (Eagly, 1987), but not completely coherent with the communal character generally attributed to women. The agentic dimension of stereotypic beliefs about personal qualities, that describes primarily an assertive and controlling tendency associated with men (Roberts, 1993), is shown by the prevalence of the masculine strategies to cope with the crisis (LS men as well as HS men). But the dimension of communion as opposed to agency is associated with HS women in opposition to HS men. While HS men react to the crisis by keeping more informed and participating in political life, HS women are more focused on sharing behaviors. At the same time, we cannot find the same relevance of the communal dimension for LS women, although they are positioned, as HS women, on the negatively defining and resigned pole.

It should be noticed that HS men are associated with the strategy of Helping the weakest, materially and morally. Even if this represents a sort of "caring" strategy, it is less involving than Share something with others. In fact, as reported by Eagly (1987) in this regard, women are more compassionate and more empathetic than are men. Men's conception of involvement with others is instead more tied to a qualification of identity rather than its realization (Gilligan, 1982). Helping distant others (the weakest) instead of share something with them, is a strategy probably more functional to the personal identity construction than a real involvement towards others' condition.

This opposition between being, more or less, compassionate and more or less involved in the relationship with the other also reminds of the collective versus individualistic norms dichotomy that characterizes cultural as well 
as gender representations (Harding, 1986; Lorenzi-Cioldi, 2009; Lorenzi-Cioldi, \& Dafflon, 1998; Markus, \& Oyserman, 1989). Here, in fact, HS men are more involved in acting, getting informed and involved in the political dynamics, coherently with the idea that individuals in western cultures, as well as men, perceive themselves as full-fledged persons who can contribute with their idiosyncrasies to the good functioning of the society at large. Instead, HS women are more engaged in sharing with others. According to this idea, in fact, individuals in non-western cultures, as well as women, perceive themselves and are perceived by others as persons who occupy well-defined places in a community, where they are in the condition to bring their contribution to its harmony and good functioning. This opposition can thus be found in a western country (as is Italy, in the present case) where individualistic tendencies are prevalent and deemed desirable. This norm is over-valued when it is associated with men (Guimond, Chatard, \& Lorenzi-Cioldi, 2013; Lorenzi-Cioldi, \& Dafflon, 1998).

Moreover, according to Gilligan (1982), HS women (on the macro and abstract side) show values that, in contrast to men, are more oriented toward collective responsibilities in an ethic of care, although these women position themselves on the same abstract level of thinking. Their ethic, in fact, does not consist of a responsiveness to others that impedes a recognition of the self, but it corresponds to the "realization that self and other are interdependent and that life, however valuable in itself, can only be sustained by care in relationship" (Gilligan, 1982, p. 127).

Nevertheless, while this kind of ethic of care is generally associated with a concrete or contextual moral way of thinking (Gilligan, 1982), it appears to be split between LS women, on the micro and practical pole, and HS women, on the abstract and sharing pole.

In summary, HS men reveal themselves as the most stereotypically coherent group, proactive and idealistic. They oppose on the one hand to HS women, who are more communal but idealistic, and on the other hand to LS women, who are more practical but not communal.

These fluctuating positioning, maybe could be explained by the typical configuration of the context of data construction: in the last decades, in Italy, women's work changed significantly. Women begin to invest massively in education and in the labour market, not only by entering more often, but also by staying longer, that is, by reducing interruptions around marriage or the birth of children, or by reducing the duration of interruptions themselves. As highlighted by Mencarini and Solera (2011), the growth in the offer of women's work, have contributed transformations not only in women's desires, identities and practices, as well as in their political visibility, but also in the demand for work, with the growth of "women's friendly" sectors, in particular the tertiary sector (especially public), even if in a more contained and more territorially dis-homogeneity, compared to other European countries.

Starting from the nineties, compared to a stable male employment rate, there is a more substantial increase in female participation in the labour market.

"The reflection of the social sciences on the "feminization" of work has produced concepts through which to interpret the data, which show how the participation of women is marked by a vulnerability due to both to segregation phenomena rather than to discontinuous workplaces, in a labor market structure not very permeable to women's needs, bound to keep family and work life together. The crux of conciliation and the ways in which it has been dealt with, are the mirror of the stickiness of a labor market that continues to represent female unemployment as less serious than male unemployment. Here with the outbreak of the crisis reappears the idea that women still have an exit strategy, instead denied to men whose role as breadwinner is still firmly part of a shared imagination that 
shapes the choices of public policies since 2008, [in our Country]. There is a dominant rhetoric about the economic crisis that wants the male labor force more penalized than the female one. Recent data on the national labor market trend reinforce this assumption, underlining the increased work participation of Italian women from the principle of the crisis. The expulsion of men would therefore seem to have benefited women. In fact, if overall in the period 2008-2014 Italian employment fell more than the European average (respectively $-2.9 \%$ and $-0.8 \%$ ), the data by gender clarifies that this decrease is mainly attributable to male employees (- $5.5 \%)$, more present in the sectors most affected by the crisis." (Farina \& Vincenti, 2015, pp. 100-101).

The interpretation of these data leads to focus on one of the main effects of the crisis, that of having strengthened the function of reserve labour or replacement that women perform on the national labour market, as a segment of labour that maintains with the market a more labile link. Together with female employment, the percentage of families in which women are the only bearer of income has increased. Despite everything, the activity rates of Italian women still remain extraordinarily low, with a gender differential which, although decreasing from 2009, measures 20 percentage points in 2014 at national level, tending to widening from North to South. More than a real change seems to emerge an overlap between old and new structural disparities determined by the economic crisis, which ends up maintaining a high gender disparity in the country (Bonomi, Brosio \& Di Tommaso, 2013; Piazzalunga \& Di Tommaso, 2015).

\section{Final remarks and future}

\section{developments}

We have illustrated that, facing a complex, crucial, but unfamiliar phenomenon, as the economic crisis, men and women define the crisis and react to it in different ways. Social representations theory offers the opportunity to see how gender stereotypes are activated and represented by common sense in facing this new and disturbing phenomenon. But this common sense is also in some way filtered by status belongings, as theorized by gender role theory (Eagly, 1987).

In our study, the classical Eagly's and Gilligan's oppositions govern the objectification of the social representations of the crisis. Men appear more proactive than women, but women do not appear more communal than men. At the same time, although our findings provide some support for Gilligan's opposition, men are not associated with the more abstract thinking, and women are not associated with the practical one. However, in coherence with this model, HS women are associated with the care dimension of women's ethic, activating the communal stereotypical way of acting but in a macro and idealistic way to define the crisis. LS women, instead, appear to be coherent with the contextual, concrete part of the woman's "proclivity to reconstruct hypothetical dilemmas in terms of the real" (Gilligan, 1982, p. 101).

Thus, it seems that the social anchoring of social representations of the economic crisis is influenced by gender and social status. Nevertheless, the difference in status modifies the stereotypical dimensions, also coherently with predictions derived from gender role theory about the reduction of the impact of gender stereotypes when men and women occupy similar social positions (Lorenzi-Cioldi, 1997). The idea that social status overrides or accounts for gender effects is testified by the fact that the most congruent roles, HS men on the one hand and LS women on the other hand, produced the strongest contrast.

In sum, the main findings of the present survey show gender and status differences in the ways participants define and foresee strategies to face the crisis, providing some insights into the social psychology of gender dynamics as related to economic phenomena.

Maybe it would be better, in this regard, to refer to other constructs like gender traits acti- 
vation. We could verify how a specific set of traits masculine/feminine really fits with the tendency to be agentic/resigned or abstract/ practical economic definitions and strategies, and how they interact with social status (both educational and economic). We could finally obtain new evidence beyond the traditional stereotypical expectation about women as having a communal/practical tendency versus the agentic/abstract men one, in facing economic phenomena. Being a woman does not necessary mean just being more oriented to others or being practically functional, those seem to condemn women to be mother and housekeepers. These characteristics, differently combined with status conditions and specific traits, could show up the particular and strategically different way women use to face with economic phenomena. So not only a different "voice", as identified by Gilligan, but a different "savoir-faire" to be scientifically legitimated with reference to economic behaviors. Political actors as well as employers, but also husbands, fathers and women themselves, could have proofs of how women can represent an active and creative resource in their managing of large scale economic phenomena. The "homo oeconomicus" probably has a "mulier oeconomica" that can have different strategic thinking and consequent behaviors, which could enrich finance as well as economics and political fields. The integration of finance and economics with social psychology, and social representations in particular, in studying such complex economic phenomena could shed light on how these common "mulieres oeconomicae" think, act, represent their selves, and are represented by others related economic phenomena. If actually neuroeconomics seems to refer mostly to the biological activation of parts of brain, we believe that the activation of parts of culture, by common sense working, is equally crucial in investigating social behavior and ameliorating the scenario in which it takes place.

Considering the limitations of the research, it seems important to underline that our status measure was based on participant education, exclusively. More direct status measures should also be considered, notably professional status, income and economic literacy (Sepúlveda Maldonado, Denegri Coria, Orellana Calderón, Criado, Mendoza, Salazar, \& Yung, 2017). The economic standing of people, crossed with their educational level, could be helpful to devise more precise hypotheses on the impact of gender on both the agentic/resigned and abstract/practical dimensions. It would be important to verify the effective moderating role of social status in this relation, to supply further evidence to the practical implication of social role theory, which states that weaker differentiation between men and women's occupational roles and status, across societies, would be associated with a decrease in gender differences (Guimond, Chatard, \& Lorenzi-Cioldi, 2013).

According to the European Commission Report (2013), devastating phenomena like the economic crisis offer opportunities for radical change, including a potential to advance equality for women and men. But our findings show that gender should not be the exclusive focus of interventions. In fact, demonstrations of the moderating role of social status have the potential to disconfirm stereotypical expectations about the sexes. They substantiate the hypothesis that differences between men and women are not just a matter of gender membership. 


\section{References}

Abric, J.C. (2003). La recherche du noyau central et de la zone muette des représentations sociales. In J.C. Abric (Ed.), Méthodes d'étude des représentations sociales (pp. 59-80). Ramonville Saint-Agne, FR: Érès.

Altieri, G. (2009). Un mercato del lavoro atipico. Storia ed effetti della flessibilità in Italia. Collana Studi e Ricerche Ies. Roma, IT: Ediesse.

Altieri, G. (2010). L'occupazione femminile in tempo di crisi: nuove segmentazioni e vecchie contraddizioni. La Rivista delle Politiche Sociali, 4, 205-227.

Bardin, L. (2003). L'analyse de contenu et de la forme de communications. In S. Moscovici \& F. Buschini (Eds.), Les méthodes des sciences humaines (pp. 243-269). Paris, FR: PUF.

Boeri, T. (2009). La crisi non è uguale per tutti. Milano, IT: Rizzoli.

Braveman, P.A., Cubbin, C., Egerter, S., Chideya, S., Marchi, K.S., Metzler, M., \& Posner, S. (2005). Socioeconomic status in health research. One size does not fit all. The Journal of the American Medical Association, 294(22), 2879-2888. doi: 10.1001/jama.294.22.2879

Bonomi, G., Brosio, G., \& Di Tommaso, M.L. (2013). The Impact of Gender Quotas on Votes for Women Candidates: Evidence from Italy. Feminist Economics, 19(4), 48-75.

Diekman, A.B., \& Eagly, A.H. (2000). Stereotypes as dynamic constructs: Women and men of the past, present, and future. Personality and Social Psychology Bulletin, 26(10), 11711188.

Doise, W. (1990). Les reprèsentations sociales. In R. Ghiglione, C. Bonnet, \& J.F. Richard (Eds.), Traite de psychologie cognitive. Paris, FR: Dunod.

Doise, W. (1992). L'ancrage dans les études sur les Représentations Sociales. Bulletin de Psychologie, XLV, 405, 189-195.

Doise, W. (2010). Confini e identità. La costruzione sociale dei diritti umani. Bologna, IT: il Mulino.

Doise, W., Clémence, A., \& Lorenzi-Cioldi, F.
(1993). The quantitative analysis of social representations. New York, US: Hervester Wheatsheaf.

Eagly, A.H. (1987). Sex differences in social behavior: A social role interpretation. Hillsdale, NJ: Erlbaum.

Eagly, A.H. (1997). Sex Differences in Social Behavior: Comparing Social Role Theory and Evolutionary Psychology. American Psychologist, 52(12), 1383-1384.

Eagly, A.H., \& Wood, W. (2012). Social Role Theory. In P.A.M. Van Lange, A.W. Kruglanski \& T. Higgins (Eds.), Handbook of Theories of Social Psychology (pp.459-476). Thousand Oaks, CA: Sage Publications

European Commission Report (2009). Employment in Europe. Belgium, BE: European Commission.

European Commission Report (2010). Employment in Europe. Belgium, BE: European Commission.

European Commission Report (2013). The impact of the economic crisis on the situation of women and men and on gender equality policies. Luxembourg, LU: Publications Office of the European Union.

European Parliament (2013). Gender aspects of the effects of the economic downturn and financial crisis on welfare systems. Retrieved from http://www.europarl.europa.eu/RegData/ etudes/etudes/join/2013/474396/IPOLFEMM_ET \%282013 \%29474396_EN.pdf

Farina, F., \& Vincenti, A. (2015). Nuova crisi e vecchi problemi. Effetti collaterali sul lavoro delle donne. la Rivista delle Politiche Sociali, 4, 99-117.

Fasanelli, R., Tuselli, A., \& Galli, I. (2016). L'utilizzo delle Evocazioni gerarchizzate nella SWOT analysis. Una proposta di metodo misto per la valutazione degli interventi educativi. Rassegna Italiana di Valutazione, 66, 76-102. doi: 10.3280/RIV2016-066006.

Fiske, S.T., Cuddy, A.J.C., Glick, P., \& Xu, J. (2002). A model of (often mixed) stereotype content: Competence and warmth respectively follow from perceived status and competition. Journal of Personality and Social Psychology, 
82, 878-902. doi: 10.1037/0022-3514.82.6.878

Flament, C. (1962). L'analyse de similitude. Cahiers du Centre de Recherche Opérationnelle, 4, 63-97.

Galli, I. (2006). La teoria delle rappresentazioni sociali. Bologna, IT: il Mulino.

Galli, I., Geka, M., Liguori, A, \& Fasanelli, R. (2014). Social Representations of Economic Crisis in Italian and Greek Social Groups. Psychology Research, 4(12), 973-998.

Galli, I., Markova, I., Bouriche, B., Fasanelli, R., Geka, M., Iacob, L., \& Iacob, G. (2010). La représentation sociale de la crise économique dans quatre pays européens. Les Cahiers Internationaux de Psychologie Sociale, 87(3), 585-620.

Galli, I., Fasanelli, R., \& Schember, E. (2018). The construction of icons as a means of access to the social representation of culture. Culture and Psychology, 24(2), 212 - 232. doi: 10.1177/1354067X17721860

Gilligan, C. (1982). In a different voice. Psychological Theory and Women's Development. Cambridge, MA: Harvard University Press.

Guimond, S., Chatard, A., \& Lorenzi-Cioldi, F. (2013). The Social Psychology of Gender across Cultures. In M.K. Ryan \& N.R. Branscombe (Eds.), The SAGE Handbook of Gender and Psychology (pp. 216-233). Los Angeles, US: SAGE Publications.

Harding, S. (1986). The science question in feminism. Ithaca, NY: Cornell University Press.

Istat (2011). Rapporto annuale. Roma, IT: Istat.

Kirchler, E. (2007). The Economic Psychology of Tax Behavior. New York, US: Cambridge University Press.

Liguori, A, Galli, I., Fasanelli, R., \& Iacob, L.M. (2014). Lay representations of an economic global crisis among different Italian and Romanian social groups. Annals of The Alexandru Ioan Cuza - Psychology Series, 23(2), 5-46.

Lorenzi-Cioldi, F. (1997). Questions de méthodologie en sciences sociales. Lausanne et Paris, FR: Delachaux and Niestlé.

Lorenzi-Cioldi, F. (2009). Dominants et dominés. Les identités des collections et des agrégats. Grenoble, FR: P.U.G.
Lorenzi-Cioldi, F., \& Dafflon, A.-C. (1998). Norme individuelle et norme collective, I: Représentations du genre dans une société individualiste. Swiss Journal of Psychology, 57 (2), 124-137.

Malach Pines, A., Lerner, M., \& Schwartz, D. (2010) Gender differences in entrepreneurship: Equality, diversity and inclusion in times of global crisis. Equality, Diversity and Inclusion: An International Journal, 29(2), 186-198. doi: 10.1108/02610151011024493

Markus, H., \& Oyserman, D. (1989). Gender and thought: The role of the self-concept. In M. Crawfors \& M. Hamilton (Eds.), Gender and thought (pp. 100-127). New York, US: Springer.

Marzana D., Pozzi M., Fasanelli R., Mercuri F., \& Fattori F. (2016). The Relation Between Participatory Social Practices and Social Representations of Citizenship in Young Adulthood. Voluntas, 27, 1152-1170. doi: 10.1007/s11266015-9607-x

Mencarini, L. \& Solera, C. (2011). Percorsi verso la vita adulta tra lavoro e famiglia: differenze di genere, istruzione e coorte (pp. 175-209). In N. Sartor, A. Schizzerotto \& U. Trivellato (Eds.), Le disuguaglianze tra le generazioni nell'Italia di oggi. Bologna, IT: Il Mulino.

Moscovici, S. (1961/1976). La psychanalyse, son image et son public. Paris, FR: P.U.F.

Moscovici, S. (1984a). The myth of the lonely paradigm: A rejoinder. Social Research, 51, 939-968.

Moscovici, S. (1984b). The phenomenon of social representations. In R.M. Farr \& S. Moscovici (Eds.), Social Representations (pp. 3-70). Cambridge, UK: C.U.P.

OECD (2009). Employment Outlook. Paris, FR: OECD.

OECD (2010). Employment Outlook. Paris, FR: OECD.

Piazzalunga, D., \& Di Tommaso, M.L. (2015). The Increase Of The Gender Wage Gap In Italy During The 2008-2012 Economic Crisis. Retrieved from http://www.carloalberto.org/ assets/working-papers/no.426.pdf

Puaschunder, J.M. (2012). On the Social Representations of Intergenerational Equity. Retrieved 
from http://ssrn.com/abstract=2011359. doi: 10.2139/ssrn.2011359

Ridgeway, C.L. (2001). The emergence of status beliefs: From structural inequality to legitimizing ideology. In J.T. Jost \& B. Major (Eds.), The psychology of legitimacy: emerging perspectives on ideology, justice, and intergroup relations (pp. 257-277). Cambridge, UK: C.U.P.

Roberts, J.A. (1993). Sex differences in socially responsible consumers' behavior. Psychological Reports, 73, 139- 148.

Roland-Lévy, C., \& Adair, P. (Eds.) (1998). Psychologie Economique : Théories et Applications. Paris, FR: Economica.

Sepúlveda Maldonado, J., Denegri Coria, M., Orellana Calderón, L., Criado, N., Mendoza, J., Salazar, P., \& Yung, G. (2017). Características emprendedoras personales y alfabetización económica: Una comparación entre estudiantes universitarios del sur de Chile. Interdisciplinaria, 34(1), 107-124. doi: 10.16888/interd.2017.34.1.7

Spini, D., \& Doise, W. (1998). Organising principles of involvement in human rights and their social anchoring in value priorities. European Journal of Social Psychology, 28, 603-622. doi: 10.1002/(SICI)1099-0992(199807/08)28: 4<603::AID-EJSP884>3.0.CO;2-P

Staerklé, C., Clémence, A., \& Spini, D. (2011). Social Representations: A Normative and Dynamic Intergroup Approach. Political Psychology, 32(5), 759-768.
Stephens, N.M., Fryberg, S.A., Markus, H.R., Johnson, C.S., \& Covarrubias, R. (2012). Unseen Disadvantage: How American Universities' Focus on Independence Undermines the Academic Performance of First-Generation College Students. Journal of Personality and Social Psychology, 102(6), 1178-1197. doi: 10.1037/a0027143

Vergès, P. (1994). Les représentations sociales de l'économie : une forme de connaissance. In D. Jodelet (Ed.), Les représentations sociales (pp. 387-405). Paris, FR: P.U.F. (1re éd. 1989).

Vergès, P., \& Bastounis, M. (2001). Towards the Investigation of Social Representations of the Economy: Research Methods and Techniques. In C. Roland-Lévy, E. Kirchler, E. Penz \& C. Gray, (Eds.), Everyday Representations of the Economy (pp. 19-48). Wien, AT: WUV|Universitatsverlag.

Vergès, P., \& Bouriche, B. (2009). L'analyse des données par les graphes de similitude. Sciences Humaines. Retrieved from http://www.scienceshumaines.com/textesInedits/Bouriche.pdf

Weiss, Y., \& Fershtman, C. (1998). Social status and economic performance: A survey. European Economic Review, 42, 801-820. https:// EconPapers.repec.org/RePEc:eee:eecrev:v:42: y:1998:i:3-5:p:801-820

Wood, W., \& Eagly, A.H. (2010). Gender. In S. Fiske, D. Gilbert \& G. Lindzey (Eds.), Handbook of Social Psychology (pp.629-667). New York, US: O.U.P.

Recibido: 11 de enero de 2018 Aceptado: 21 de octubre de 2019 